\title{
Dilemmatic presentation of hemangioma of the lip: A short case report
}

\author{
(1) Roopashri Rajesh Kashyap, (1) Anjana Dali Daniel, (1) Vidya Aravind Holla, (1) Raghavendra Kini, \\ (1) Prasanna Kumar Rao
}

A.J.Institute of Dental Sciences, Department of Oral Medicine and Radiology, Mangalore, India

Date submitted:

28.08.2019

Date accepted:

31.10.2019

Online publication date: 15.06.2020

\section{Corresponding Author:}

Roopashri Rajesh Kashyap MD,

A.J.Institute of Dental Sciences,

Department of Oral Medicine and

Radiology, Mangalore, India

roopashri.r.k@gmail.com

ORCID:

orcid.org/0000-0003-1601-9278

Keywords: Capillary hemangioma, lip

\begin{abstract}
The hemangioma is a hamartomatous proliferation of endothelial cells that are present at birth or can develop during the neonatal period. They pose a diagnostic dilemma when they develop in adults. This is a short case report of a case of a 21-year-old female patient presenting with a polypoid mass on the upper lip of 3 weeks duration, which was diagnosed as capillary hemangioma on histopathologic examination.
\end{abstract}

\section{Introduction}

Hemangioma is one of the most common hamartomatous growth in the orofacial region. It is mainly seen in infants and children although it is also observed in middle-aged and elderly individuals (1). However, denovo appearance of capillary hemangioma is a very rare occurrence in adults. We hereby report a case of capillary hemangioma of the lip in a female patient aged 21 years, which posed a diagnostic dilemma due to its uncommon presentation.

\section{Presentation of Case}

A 21-year-old female patient presented with the complaint of growth on the left side of the upper lip with 3 weeks duration. Her medical history revealed that it started as a white pinhead sized papule. As the patient was concerned about this, she made multiple attempts to rupture it with fingernails which traumatized the lesion and resulted in minimal bleeding. The lesion then slowly grew and attained the current size. There were no prodromal symptoms or pain associated with the lesion. General examination of the patient did not reveal any abnormalities. On examination of the lip, a well-defined reddish exophytic growth measuring about $0.4^{*} 0.6 \mathrm{~cm}$ was seen on the left side of the upper lip (Figure 1). The surface of the lesion was covered with scabs. The surrounding tissue appeared normal. It was firm, fixed and untender. Diascopy test was negative. As the features of the lesion did not match any of the known lesions and due to esthetic concern, an excisional biopsy was planned and performed by a plastic surgeon. Bleeding encountered during excision was minimal. On histopathological examination, it showed stratified squamous epithelium with underlying vascular lesion comprising of lobules of proliferating capillary sized vessels. The vessels were lined with plump endothelial cells and an intact smooth muscle layer. The lobules were separated by thin fibrous septa suggestive of capillary hemangioma (Figure 2). The patient was recalled periodically and no recurrence was observed for 18 months. 


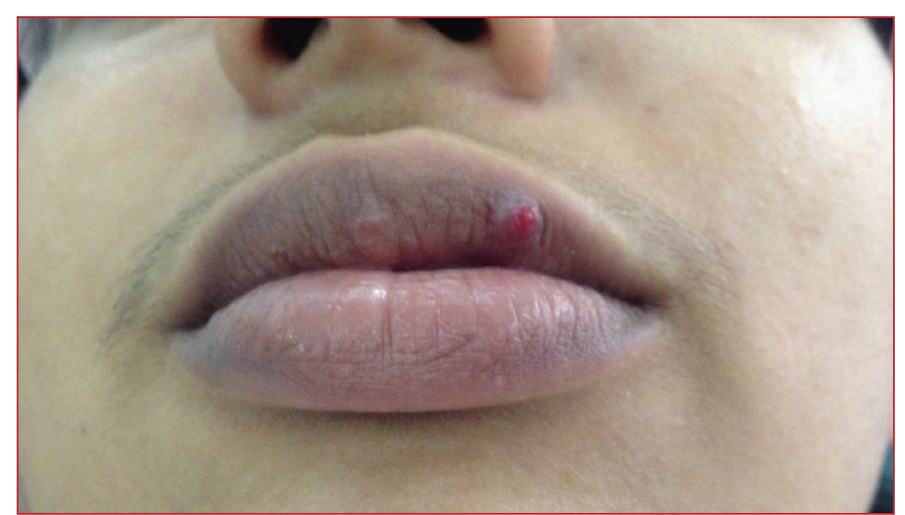

Figure 1. Well-defined reddish exophytic growth on the upper lip

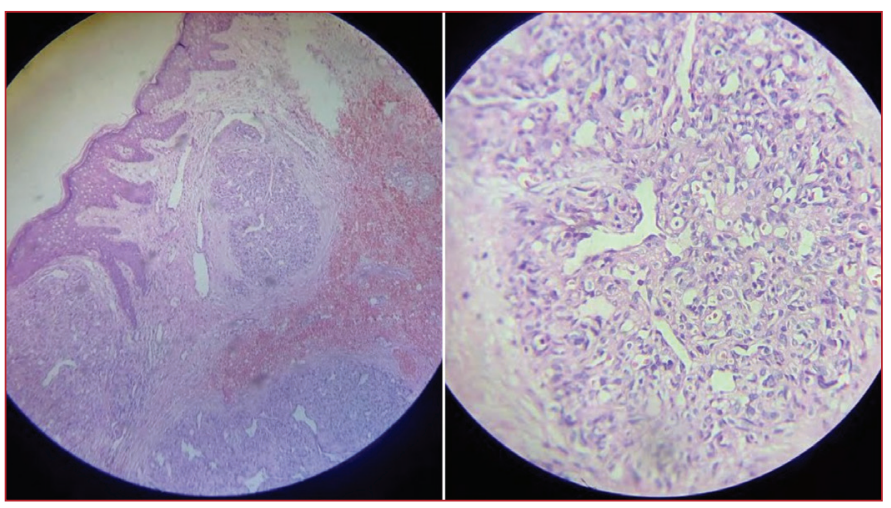

Figure 2. H\&E stained sections showing stratified squamous epithelium with underlying vascular lesion comprising of lobules of proliferating capillary sized vessels lined with plump endothelial cells

\section{Discussion}

The lip is the most common site for the occurrence of many sorts of vascular lesions probably due to the fact that lip has relatively good blood supply owing to the presence of large blood vessels approximating the surface at this location than the other parts, and that the lip is often subjected to traumatic insults (1). The hemangioma is a benign hamartomatous proliferation of endothelial cells commonly seen in the head and neck region. Hemangiomas are either present at birth or can develop during the neonatal period. These lesions are three to five times more common in females (2). It is quite uncommon to see hemangiomas arising denovo in adults and hence it poses a diagnostic challenge.

The hemangioma clinically presents as a softer, smooth or lobulated, pedunculated or sessile mass, its size may vary from a few millimeters to several centimeters, and the color may vary from pink to red-purple. They are generally painless. They are firm and rubbery to palpation (3).

Although capillary hemangioma presents as an asymptomatic lesion, its location and size may demand immediate intervention. It usually presents a diagnostic challenge to the clinician. Lesions like pyogenic granuloma may also present at such locations, but is a rare occurrence without any history of chronic irritation (4). The biopsy of such lesions is mandatory for establishing a definite diagnosis. Most importantly, the surgical excision of capillary hemangioma should be performed by considering the intra-operative and postoperative bleeding (2). The factors which direct the management of hemangiomas include the patient's age and the extent and size of the lesions, also the clinical characteristics (5). The lesions of lip may be of aesthetic concern and surgical excision is a treatment option to be considered as it also provides good esthetic and functional outcome (2). The prognosis of hemangioma, in general, is excellent since it does not tend to recur or undergo malignant transformation following adequate treatment (5). No recurrence was observed in our case as well.

\section{Conclusion}

Hemangiomas, though they are common lesions, may pose a diagnostic challenge due to its uncommon presentations. Oral physicians should be aware of variety of manifestations of such lesions to avert medical emergencies.

\section{Ethics}

Peer-review: Externally peer-reviewed.

\section{Authorship Contributions}

Surgical and Medical Practices: V.A.H., Concept: R.R.K., A.D.D., Design: R.R.K., A.D.D., Data Collection or Processing: R.R.K., A.D.D., V.A.H., Analysis or Interpretation: R.R.K., R.K., P.K.R., Literature Search: R.R.K., R.K., P.K.R., Writing: R.R.K., R.K, P.K.R.

Conflict of Interest: No conflict of interest was declared by the authors.

Financial Disclosure: The authors declared that this study received no financial support.

\section{References}

1. Shimoyama T, Horie N, Kato T, Kaneko T, Ide F. Cellular hemangioma in an adult. J Oral Sci. 2000;42:177-180.

2. Smitha K, Chatra L. Capillary hemangioma of the lower lipa rare case report in male. World Journal of Pharmaceutical Research. 2017;3:310-312.

3. Desai V, Narang P, Varma B, Maghu S. Unusual site of capillary hemangioma: Practitioner's dilemma! Chrismed J Heal Res. 2015;2:77-81.

4. Poudel P, Chaurasia N, Marla V, Srii R. Pyogenic granuloma of the upper lip: A common lesion in an uncommon location. J Taibah Univ Med Sci. 2019;14:95-98.

5. Rathod V, Verma C, Sharma S, Mala S. Hemangioma of Left Buccal Mucosa: A Case Report. Arch of Dent and Med Res. 2016;2:61-65. 